\title{
ASSISTÊNCIA ESTUDANTIL E ALIMENTAÇÃO ESCOLAR: REFLEXÕES BASEADAS EM UM TRABALHO INTERDISCIPLINAR
}

\author{
STUDENT ASSISTANCE AND SCHOOL FOOD: REFLECTIONS BASED ON \\ INTERDISCIPLINARY WORK
}

\author{
Alessandra Barreto Paravidino ${ }^{1}$ \\ Débora Spotorno Moreira Machado Ferreira ${ }^{2}$ \\ Jéssica Oliveira Monteiro ${ }^{3}$
}

Felicidade, passei no vestibular

Mas a faculdade é particular

Livros tão caros tanta taxa pra pagar

Meu dinheiro muito raro

Alguém teve que emprestar

Morei no subúrbio, andei de trem atrasado

Do trabalho ia pra aula, sem

Jantar e bem cansado

Mas lá em casa à meia-noite tinha

Sempre a me esperar

Um punbado de problemas e criança pra criar ${ }^{4}$

Martinho da Vila

RESUMO: $\mathrm{O}$ artigo tem como objetivo refletir alguns elementos sobre assistência estudantil e a alimentação escolar, como medidas essenciais no campo do direito à educação. Para isso, o caminho metodológico percorrido foi a recuperação de uma experiência de trabalho interdisciplinar, entre as áreas de Serviço Social e Nutrição, com a criação e desenvolvimento do Programa de Segurança Alimentar e Nutricional no IFFluminense Campus Macaé durante a pandemia de COVID-19, problematizada à luz de referências teóricas e normativas sobre as temáticas envolvidas. Destacam-se algumas conclusões relevantes que esse trabalho alcançou: a importância do debate sobre a estreita relação entre as políticas de assistência estudantil e de alimentação escolar; a relevância do trabalho interdisciplinar na assistência estudantil e a

\footnotetext{
${ }^{1}$ Nutricionista do IFFluminense - Campus Macaé desde 2010, graduada em Nutrição pela Universidade do Estado do Rio de Janeiro - UERJ e pós-graduada em Nutrição Clínica Funcional pela Universidade Cruzeiro do Sul - UNICSUL. E-mail: aparavidino@iff.edu.br

${ }^{2}$ Assistente Social do IFFluminense - Campus Macaé, atua na política de educação desde 2010, mestre em Serviço Social pela UFJF, autora do livro Perspectivas da Formação em Serviço Social no Brasil em tempos de contrarreforma da educação superior (Novas Edições Acadêmicas, 2015). E-mail: deboraspotorno@gmail.com

${ }^{3}$ Assistente Social em exercício no IFFluminense - Campus Macaé. Mestre em Serviço Social pela Universidade Federal do Rio de Janeiro. E-mail: jessica.monteiro@iff.edu.br

4 "O Pequeno Burguês", de Martinho da Vila. A canção remete-se à vivência de um sujeito pobre em uma "faculdade particular". Ainda que o presente artigo refere-se a instituições de ensino públicas, a analogia nos serve poeticamente para a crítica sobre as condições de permanência e êxito escolar do alunado proveniente das classes populares.
} 
necessidade de fortalecimento de concepções e práticas concretas que considerem a diversidade de ações que implicam a garantia de permanência no âmbito escolar, para além das bolsas e auxílios financeiros.

Palavras-chave: Assistência Estudantil; Alimentação Escolar; Educação.

\begin{abstract}
The article aims to reflect some elements on student assistance and school meals, as essential measures in the field of the right to education. For this, the methodological path followed was the recovery of an interdisciplinary work experience, between the areas of Social Service and Nutrition, with the creation and development of the Food and Nutritional Security Program at the Macaé Campus of IFFluminense during the COVID pandemic. -19, problematized in the light of theoretical and normative references on the themes involved. Some relevant conclusions that this work reached are highlighted: the importance of the debate on the close relationship between the policies of student assistance and school meals; the relevance of interdisciplinary work in student assistance and the need to strengthen concrete concepts and practices that consider the diversity of actions that imply the guarantee of permanence in the school environment, in addition to scholarships and financial aid.
\end{abstract}

Keywords: Student Assistance; School Feeding; Education.

\title{
INTRODUÇÃO
}

A assistência estudantil é um elemento fundamental para materialização do direito social à educação. No Brasil, tais ações estão respaldadas, de modo mais amplo, pela Constituição Federal de 1988 e pela Lei de Diretrizes e Bases da Educação Nacional (Lei 9.394/1996). Isso porque, quando falamos em educação, além das questões relacionadas ao ensino, há aquelas que dizem respeito às condições de permanência e êxito no âmbito escolar. De modo mais específico, no recorte deste texto, referenciamos o Programa Nacional de Assistência Estudantil (PNAES), disposto no Decreto 7.234/2010 e o Programa Nacional de Alimentação Escolar (PNAE), disposto na Lei No 11.947/2009, como marcos regulatórios cruciais para a problematização da discussão proposta.

No Instituto Federal Fluminense (IFFluminense), a assistência estudantil é regulamentada pela Resolução N 39/2016, que a inscreve na perspectiva de um conjunto de ações, serviços e projetos que visa possibilitar a democratização das condições de acesso, permanência e conclusão de curso pela minimização dos efeitos e impactos da desigualdade social estrutural na vida dos estudantes e suas famílias (IFFLUMINENSE, 2016). Áreas como 
alimentação; transporte; cultura; saúde; esporte; apoio pedagógico, social e psicológico; etc $^{5}$., fazem parte dessa política que, em cada unidade, é gerida e operacionalizada por uma equipe multiprofissional.

Sendo assim, uma leitura cuidadosa das legislações e regulamentações em questão e a observação empírica das demandas que chegam aos setores que trabalham com a assistência estudantil dentro da instituição, mostram que as necessidades estudantis estão para além do que se pode atender com benefícios financeiros, resultantes de análises socioeconômicas.

Neste artigo, buscamos refletir sobre questões abordadas na política de assistência estudantil e na alimentação escolar a partir de uma experiência de trabalho interdisciplinar, envolvendo as áreas de Serviço Social e Nutrição do Campus Macaé do IFFluminense durante a pandemia do COVID-19, que vem trazendo drásticos impactos nas condições de vida da população. Tais reflexões implicam, também, questões para além desse período de excepcionalidade.

No contexto da assistência estudantil, buscamos atentar para a discussão sobre a alimentação escolar diante das especificidades dos Institutos Federais de Educação, Ciência e Tecnologia (IFET’s), que oferecem educação básica e superior. Problematizar suas diferenças não significa apartar suas ações, mas reconhecê-las, inclusive para pensar em caminhos para garantia de direitos. Os marcos regulatórios que se dispõem trazem impactos contundentes para a oferta de ações junto a heterogeneidade de modalidades e níveis de ensino que abarcam os IFET's.

Para fim de exposição, dividimos o texto em três tópicos: o primeiro visa refletir questões acerca da assistência estudantil e a alimentação escolar, na perspectiva do direito à educação; o segundo objetiva socializar uma experiência de trabalho conjunto entre assistentes sociais e nutricionista da Coordenação de Políticas de Assistência Estudantil do IFFluminsense - Campus Macaé, com a criação e desenvolvimento do Programa de Segurança Alimentar e Nutricional (PSAN) no período de pandemia; e o terceiro que pontua e sintetiza alguns aprendizados nesse processo, buscando mais do que "pontos de chegada", mas "pontos de partida" para futuros ensaios e experiências. Estudos como Lima (2017), Pinto

\footnotetext{
5 O próprio PNAES traz esses diversos eixos como áreas de atuação. Pauta que as ações se dirigem prioritariamente a estudantes com determinado perfil: oriundos da rede pública de ensino básico ou com renda per capita familiar de até um salário mínimo e meio.
} 
(2015) e Crossara \& Silva (2020) contribuíram para a fundamentação das elaborações propostas.

Dessa maneira, como profissionais atuantes na política de assistência estudantil, percebemos que as medidas de saúde pública de isolamento social, que implicou a suspensão temporária do período letivo nas unidades da federação a fim de evitar a disseminação da infecção humana pela Covid-19, assim como as consequentes situações decorrentes da crise econômica, evidenciaram a necessidade das ações serem mais articuladas e contextualizadas. Quando pensamos sobre as ações básicas de assistência estudantil que propiciam condições adequadas aos estudantes, a alimentação escolar se apresenta de forma primordial.

\title{
A ASSISTÊNCIA ESTUDANTIL E A ALIMENTAÇÃO ESCOLAR
}

A assistência estudantil, contextualizada no PNAES, é uma política pública que vem se caracterizando, cada vez mais, pela seletividade e focalização, cujo atendimento prioritário destina-se a estudantes oriundos da rede pública de educação básica ou com renda familiar per capita de até um salário mínimo e meio. Sua regulamentação mais específica data do ano de 2010, pelo Decreto ${ }^{\circ} 7.234$, o qual diz ter por objetivo:

\begin{abstract}
Art. $2^{\circ}$ - I - democratizar as condições de permanência dos jovens na educação superior pública federal; II - minimizar os efeitos das desigualdades sociais e regionais na permanência e conclusão da educação superior; III - reduzir as taxas de retenção e evasão; e IV - contribuir para a promoção da inclusão social pela educação (BRASIL, 2010).
\end{abstract}

Trata-se de uma política de educação ${ }^{6}$, que abarca as instituições federais de ensino superior, que implicam, além das universidades públicas, os IFET’s, considerando suas especificidades (já que estes últimos, além da educação superior, ofertam também modalidades da educação básica). Apesar de ter um orçamento próprio destinado ao Programa, sua garantia

\footnotetext{
${ }^{6}$ A assistência estudantil é uma política de educação e não uma política de assistência social. Por muitas vezes, há essa confusão entre assistência estudantil e assistência social e, até mesmo, com o Serviço Social. Trata-se de áreas distintas. Assistência estudantil é uma política de educação que visa garantir condições de permanência e êxito escolar, buscando igualdade e equidade de oportunidades de acesso à educação, num contexto de tamanhas desigualdades sociais, como observado no Brasil. A assistência social, regulamentada pela Lei Orgânica de Assistência Social (LOAS-Lei 8.742/1993), integra o tripé da seguridade social no Brasil (junto à saúde e previdência social), objetivando o atendimento às necessidades sociais básicas. Já o Serviço Social é uma profissão de nível superior regulamentada pela Lei 8.662/1993, sendo o/a assistente social profissional com graduação em Serviço Social e registro no Conselho Regional de Serviço Social, podendo atuar em diversas políticas públicas como educação, saúde, assistência social, entre outras.
} 
de financiamento efetivo é inexistente. O Decreto 7.234/2010 aborda essa questão no art. $8^{\circ}$, dizendo que: "as despesas do PNAES correrão à conta das dotações orçamentária anualmente consignadas ao Ministério da Educação ou às instituições federais de ensino superior, devendo o Poder Executivo compatibilizar a quantidade de beneficiários com as dotações orçamentárias existentes[...]” (BRASIL, 2010).

Isto significa que temos a seguinte lógica: não é a demanda real dos discentes por políticas de permanência que define os recursos a serem repassados e, sim, as dotações orçamentárias repassadas que irão estabelecer a quantidade de usuários atendidos pela política de assistência estudantil. Desse modo, a assistência estudantil fica sujeita ao subfinanciamento ${ }^{7}$, dificultando e/ou inviabilizando muitas ações. Com orçamento limitado, e cada vez mais ameaçado, as ações ficam restritas às formas de bolsas e auxílios, regidas por uma acirrada seleção da pobreza e, raramente, atendendo com integralidade o seu público prioritário.

Ainda assim, mesmo diante da impossibilidade de alcance a todos que necessitam, percebemos que a política de assistência estudantil tem se caracterizado como indispensável para o acesso e, especialmente, para a permanência e o êxito escolar dos estudantes de renda baixa $^{8}$ nas Instituições Federais de Ensino. A importância de uma política pública como essa decorre do fato de que:

\footnotetext{
Para os estudantes oriundos das camadas mais pobres, somente o ingresso, em muitos casos, não se faz suficiente para a conquista da diplomação, tendo em vista que os diversos custos com a escolarização universitária poderão representar um "peso" no orçamento individual e/ou familiar, que eles podem não conseguir corresponder (PINTO, 2015, p. 66).
}

Nessa direção, a formulação a seguir é uma referência valiosa e pertinente para pensarmos em sua concepção:

\footnotetext{
${ }^{7}$ Podemos compactuar assim, com a necessidade da assistência estudantil se tornar uma política de Estado, respaldada por uma lei, com garantia de financiamento a longo prazo e aporte de recursos específicos. Destaca-se a fragilidade institucional da forma Decreto, que pode ser revogado unilateralmente pelo chefe do poder executivo com mais facilidade. Sobre esse assunto, cf. o estudo de CROSARA, D. M. \& SILVA, L.B. (2020), o qual indica a existência de doze projetos em tramitação para tornar lei o PNAES.

${ }^{8}$ A assistência estudantil no Brasil não é uma novidade, nem tampouco foi inaugurada com o PNAES. Ela tem uma trajetória histórica muito anterior. Ações como moradias, bandejões e bolsas a estudantes com perfil de renda baixa já faziam parte dos cotidianos institucionais em questão. Mas, sem uma regulamentação de caráter nacional, ficava à mercê da atenção (ou não) das gestões das unidades, cf. CROSARA, D. M. \& SILVA, L. B (2020).
} 


\begin{abstract}
A assistência estudantil é concebida como uma modalidade de política social voltada ao enfrentamento das expressões da "questão social" no interior das instituições de ensino e está associada ao universo de constrangimentos que os estudantes, oriundos da classe trabalhadora, se defrontam para permanecer estudando. Tais constrangimentos se expressam pelos numerosos carecimentos materiais que esses discentes atravessam no seu cotidiano quanto ao transporte, à alimentação, ao material didático e à moradia ou, ainda, nos mecanismos de exclusão operados nessas instituições com base na origem de classe, na trajetória escolar, na identidade étnico-racial, nas relações de gênero e na orientação sexual (LIMA, 2017, p. 120).
\end{abstract}

Por outro lado, mas em um horizonte comum de garantias no campo educacional, a alimentação escolar, atualmente disposta pelo PNAE, em seu art. $4^{\circ}$, demarca que:

Tem por objetivo contribuir para o crescimento e o desenvolvimento psicossocial, a aprendizagem, o rendimento escolar e a formação de hábitos alimentares saudáveis dos alunos, por meio de ações de educação alimentar e nutricional e da oferta de refeições que cubram suas necessidades nutricionais durante o período letivo (BRASIL, 2009).

A alimentação é um direito social, estabelecido no art. $6^{\circ}$ da Constituição Federal Brasileira, alterado posteriormente pela Emenda Constitucional $n^{\circ} 64$ de 4 de fevereiro de 2010, que coloca como dever do poder público a adoção de políticas e ações que se façam necessárias para promover e garantir a segurança alimentar e nutricional da população. Tal garantia se encontra regulamentada na Lei n ${ }^{\circ}$ 11.346/2006, conhecida como Lei Orgânica de Segurança Alimentar e Nutricional (LOSAN), que define Segurança Alimentar e Nutricional (SAN) como:

\footnotetext{
Realização do direito de todos ao acesso regular e permanente a alimentos de qualidade, em quantidade suficiente, sem comprometer o acesso a outras necessidades essenciais, tendo como base práticas alimentares promotoras de saúde, que respeitem a diversidade cultural e que sejam social, econômica e ambientalmente sustentáveis (BRASIL, 2006).
}

O PNAE coloca a alimentação escolar como direito dos estudantes da educação pública básica e como dever do Estado garanti-la. Assim, diferentemente do PNAES, o PNAE possui um alcance universal, destituído de recortes de prioridades para o seu atendimento.

Portanto, compreendemos que, além do acesso a uma educação básica e de qualidade, garantir o acesso às necessidades nutricionais mínimas durante o período letivo, também é papel da escola e condição sine qua non para a permanência e o aprendizado dos estudantes. 
Dessa forma, esses dois temas (a assistência estudantil e a alimentação escolar), são elementos fundamentais para materialização do direito social à educação. Entretanto, as atuações profissionais no âmbito dos IFET's, possuem especificidades decorrentes dos diferentes níveis e modalidades de ensino existentes. Em termos de previsões legais, existem particularidades para a oferta dessas ações aos diferentes níveis de ensino.

No que se refere à política de alimentação para a educação básica, a Lei $\mathrm{N}^{\circ}$ 11.947/2009, do PNAE, estabelece a alimentação como um direito e aponta como diretriz a universalidade do atendimento. Na educação superior, sua previsão encontra-se no Decreto 7.234/2010, do PNAES, que embora indique a alimentação como uma das áreas de atuação da assistência estudantil, sua garantia está marcada pela seletividade, devido à priorização do atendimento a estudantes com renda per capita familiar de até um salário mínimo e meio e/ou oriundos da rede pública de ensino. Neste caso, numa situação de insuficiência de recursos financeiros para atender à demanda prioritária total, a qual o Programa se dispõe atender, a ação assume caráter não universal, distinto do previsto à educação básica.

Assim, temos em uma mesma unidade escolar: a educação básica (ensino médio e técnico), com garantia legal pelo PNAE para oferta universal da alimentação escolar; e a educação superior (graduações) com sua previsão como um dos eixos do PNAES, porém, de forma seletiva e focalizada. O provimento da assistência estudantil precisa considerar essas especificidades dos IFET’s, decorrentes dos diferentes níveis de ensino e modalidades existentes. Tal diversidade impõe às instituições a necessidade de desenvolver mecanismos e políticas de atendimento que contemplem de forma isonômica todos os estudantes, sem perder de vista as regulamentações específicas.

Quando falamos do direito à alimentação de maneira universal, temos entendido que apesar da política de assistência estudantil abarcar a alimentação condicionada a um perfil prioritário, tal fato não deve se sobrepor à discussão de sua universalização aos alunos da educação básica mesmo que, para isso, não seja a rubrica orçamentária específica do PNAES a única ou a principal fonte para manter as despesas dessa universalização. Assim, os IFET’s precisam, urgentemente, atentar para o fato de que o atendimento via edital, por meio de análise socioeconômica, não suprime a necessidade de universalização dessa política a quem lhe é de direito. 


\section{TRABALHO INTERDISCIPLINAR EM TEMPOS DE PANDEMIA: O PROGRAMA DE SEGURANÇA ALIMENTAR E NUTRICIONAL}

Neste tópico, trataremos sobre a articulação de um trabalho interdisciplinar no IFFluminense, Campus Macaé, destacando a necessidade de implementação de medidas imediatas, inéditas e emergenciais no contexto da pandemia. As ações partem da iniciativa dos profissionais da assistência estudantil do campus, mais especificamente de assistentes sociais e nutricionista, articulando com a gestão da escola e setores de transporte e de tecnologia da informação.

Diante dos impactos econômicos e sociais em decorrência da disseminação da Covid-19 e da necessidade imediata de atender os estudantes que se encontram afastados das atividades escolares presenciais, mediante os recursos disponíveis, a referida equipe técnica se reuniu com os gestores do campus a fim de identificar possibilidades de ação e atendimentos aos estudantes.

Assim que se instalou a suspensão das aulas, a equipe de assistência estudantil, atenta à realidade dos estudantes e considerando a Nota Pública emitida pelo Conselho Federal de Nutricionistas (CFN, 2020), que alertou "para a necessidade de políticas de segurança alimentar e nutricional neste momento em que uma parcela significativa da população brasileira se encontra em situação de vulnerabilidade social”, desenvolveu ações de caráter emergencial, como a distribuição de gêneros alimentícios em estoque adquiridos com recursos do PNAE $^{9}$ e a convocação de alunos em lista de espera para recebimento da bolsa permanência em caráter emergencial, atendendo os estudantes avaliados por editais de bolsas e auxílios de assistência estudantil, além dos recém matriculados, que ainda não tinham suas realidades analisadas por estudo socioeconômico.

As bolsas e auxílios de assistência estudantil, custeadas com a fonte do PNAES, foram mantidas nas modalidades Auxílio Moradia, Bolsa Permanência e Bolsa Educação para Necessidades Especiais. As novas medidas não impediram a manutenção de ações já desenvolvidas pela assistência estudantil. $\mathrm{O}$ auxílio alimentação (que consiste no custeamento de uma refeição almoço no restaurante terceirizado existente na escola) e o auxílio transporte (que consiste no repasse de valor de passagem para acesso a escola em tempos de atividades letivas presenciais) foram direcionados para atendimento de auxílios de assistência estudantil de caráter emergencial neste período de suspensão das atividades presenciais.

\footnotetext{
9 Autorizado em caráter excepcional de suspensão das aulas em razão de situação de emergência ou calamidade pública, pela Lei n. ${ }^{\circ} 13.987 / 2020$.
} 
Importa destacar que os estudantes do Campus Macaé, em funcionamento ordinário, têm disponíveis três lanches diários (ofertados através do PNAE) e, aqueles com perfil PNAES de até um salário mínimo e meio, inscritos em edital de bolsas e auxílios de assistência estudantil, também recebem almoço através do referido auxílio alimentação, financiado por recursos advindos do PNAES e do custeio geral do campus.

Uma vez encerrado o estoque de alimentos do campus e sem a previsibilidade do fim da pandemia, percebeu-se a necessidade de uma alternativa de atendimento permanente às novas demandas dos estudantes. Observamos que, apesar da manutenção do atendimento de diversas das modalidades de benefícios de assistência estudantil, a alimentação escolar não estava contemplada entre aqueles que permaneceram sendo garantidos durante a suspensão das aulas (devido sua natureza se tratar de oferta de prato de comida em restaurante terceirizado cujo funcionamento inclusive permanece suspenso). Além disso, devido à pandemia, os estudantes (inscritos ou não em editais de assistência estudantil) poderiam sofrer alterações significativas em suas situações socioeconômicas. Da mesma maneira, era necessária a atenção aos estudantes recém ingressados na escola, pois ainda se encontravam fora dos processos ordinários de editais de análise socioeconômicas.

Nesse sentido, a ausência das aulas presenciais não apenas traz prejuízos do ponto de vista da obtenção de conhecimento, do andamento do ano letivo, do cumprimento do currículo, do preparo para o ENEM, mas também do ponto de vista da garantia da segurança nutricional e alimentar dos estudantes, já que passam grande parte dos seus dias no ambiente escolar e a alimentação estudantil contribui para sua permanência e formação integral. Sendo assim, a modificação na rotina escolar, com suspensão indeterminada do calendário acadêmico, impacta a vida de muitos estudantes de famílias de renda baixa, em que a merenda é a única ou a mais importante refeição do dia.

O PNAE (Programa Nacional de Alimentação Escolar) beneficia hoje cerca de 41 milhões de estudantes no Brasil. Para muitos deles, é na escola que encontram a única refeição do dia. Das mais de 54 milhões de pessoas que vivem na extrema pobreza no Brasil hoje, 14 milhões têm menos de 14 anos, segundo dados do IBGE $\left(\right.$ GOMES, 2020) ${ }^{10}$.

Assim, as assistentes sociais e nutricionista do campus, por meio de um estudo interdisciplinar e com respaldo da gestão (Diretoria de Políticas Estudantis, Diretoria de

${ }^{10}$ Artigo disponível como matéria no Jornal Brasil de Fato, cf. referências bibliográficas ao final do artigo. 
Administração e Diretoria Geral), propôs a criação do Programa de Segurança Alimentar e Nutricional (PSAN), de caráter emergencial e temporário, com o objetivo de garantir a alimentação básica aos discentes do campus e seus membros familiares, considerando as condições socioeconômicas e nutricionais em que se encontram.

O Programa permitiu de uma maneira mais eficaz e menos injusta, o alcance de atendimento a todos os alunos matriculados no Campus Macaé, e não apenas aos presentes em listas de espera de editais anteriores.

Acerca da alteração socioeconômica vivida pelos estudantes em decorrência da pandemia, a percepção profissional se dava devido aos relatos dos estudantes sobre essas mudanças às assistentes sociais, com vistas a atualizar seus estudos socioeconômicos. Posteriormente, em uma pesquisa realizada também pelas assistentes sociais da unidade, constatou-se que mais de 50\% das famílias dos respondentes haviam tido o seu sustento afetado durante a pandemia ${ }^{11}$. Quase $60 \%$ relataram que a vida foi afetada especificamente por situação de desemprego próprio ou de algum membro da família. Contribuindo para o agravo da situação de insegurança alimentar e nutricional da população ${ }^{12}$, destaca-se a alta no preço de alimentos básicos, que tem sido recorrente neste período.

\begin{abstract}
Segundo o IBGE, a inflação medida pelo Índice de Preços ao Consumidor Amplo (IPCA) de agosto foi de $0,24 \%$, a maior alta para o mês em quatro anos, influenciada principalmente por alimentos e bebidas, que tiveram incremento de $0,78 \%$ no período, e pelos transportes $(0,82 \%)$. No acumulado do ano, os alimentos que mais encareceram foram cebola $(50,40 \%)$, leite longa vida $(22,99 \%)$, arroz $(19,25 \%)$ e óleo de soja $(18,63 \%)$ - este último, ficou $9 \%$ mais caro só no mês passado (LINDER, 2020) ${ }^{13}$.
\end{abstract}

Conforme edital do Programa ${ }^{14}$, as ações de atendimento previstas são múltiplas, se configurando como uma política emergencial contínua enquanto permanecer a suspensão das aulas presenciais. São elas: 1) auxílio financeiro emergencial aos estudantes inscritos e/ou habilitados no valor de $\mathrm{R} \$ 200,00$ (duzentos reais) por mês; 2) repasse de kits de alimentos, de

\footnotetext{
11 Pesquisa sobre condições dos discentes do IFF, Campus Macaé, no período da pandemia. Disponível em: http://portal1.iff.edu.br/nossos-campi/macae/noticias/pesquisa-aponta-condicoes-dos-discentes-de-macae-napandemia $\mathrm{O}$ objetivo da pesquisa foi conhecer as condições de vida e de saúde dos discentes no momento de isolamento social e utilizar as informações como instrumento norteador das ações pelas equipes de profissionais do campus.

12 "Mesmo com o auxílio emergencial, estamos prevendo que o Brasil esteja voltando para o Mapa da Fome", afirma a antropóloga Maria Emília Pacheco, ex-presidente do Conselho Nacional de Segurança Alimentar (Consea) e membro do Fórum Brasileiro de Soberania e Segurança Alimentar e Nutricional (FBSSA)( LINDER, 2020).

${ }^{13}$ Matéria publicada no Uol Economia, cf. referências bibliográficas ao final do artigo.

14 Edital do PSAN disponível em: http://selecoes.iff.edu.br/assistencia-
}
estudantil $/ \mathrm{macae} / 2020 /$ processo seletivo-3 
acordo com a classificação dos estudantes segundo a Escala Brasileira de Insegurança Alimentar (EBIA) ${ }^{15}$ e com a disponibilidade dos itens alimentícios fornecidos à escola; 3) orientações nutricionais, assistenciais e articulações possíveis com a rede de políticas públicas municipais àqueles que necessitem.

Para o financiamento do PSAN, participam os recursos do PNAE (na aquisição de gêneros alimentícios para montagem de kits de alimentos), os recursos do custeio geral do campus e os recursos do PNAES $^{16}$ (para o pagamento do auxílio financeiro).

A inscrição no Programa pelos estudantes acontece por meio de questionário "Google Forms" por fluxo contínuo, ou seja, o estudante pode se inscrever a qualquer momento que sentir necessidade. Além de dados pessoais e acadêmicos, é aplicado o questionário da EBIA, que mede diretamente a percepção e vivência de insegurança alimentar e fome no nível domiciliar, como também colocadas outras perguntas sobre a condição socioeconômica, como a origem escolar antes de ingressar ao IFFluminense (rede pública ou particular), quantidade de pessoas na família, renda mensal do grupo familiar, existência de menores de 18 anos e idosos na família e atendimento ou não em programa assistencial do governo.

A análise dos inscritos no Programa, devido à emergência da situação e ao caráter do atendimento, é feita por um processo simplificado e menos burocrático, de modo interdisciplinar, onde cabe à profissional de Nutrição analisar as questões específicas sobre segurança alimentar e nutricional e às profissionais de Serviço Social, analisar as questões socioeconômicas declaradas pelos estudantes cadastrados.

Para classificação dos estudantes, utiliza-se a EBIA e a análise dos dados socioeconômicos, considerando indicadores já utilizados no Programa de Assistência Estudantil. A equipe envolvida também se reúne mensalmente para trocas de percepções, ponderações e planejamento das ações possíveis de atendimento em cada mês.

A ação de repasse dos kits de alimentos merece ser ressaltada porque o quantitativo de estudantes atendidos foi se elevando, chegando a somar cento e vinte estudantes em outubro de 2020, aumentando também a complexidade na logística da entrega à domicílio ${ }^{17}$. Para isso,

\footnotetext{
15 A Escala Brasileira de Insegurança Alimentar (EBIA) é uma escala psicométrica, que avalia de maneira direta uma das dimensões da segurança alimentar e nutricional em uma população, por meio da percepção e experiência com a fome. Estudo Técnico No 01/2014, cf. referências bibliográficas.

${ }^{16} \mathrm{O}$ PSAN está alinhado com o PNAES, cabendo às instituições federais de ensino definir os critérios e a metodologia de seleção dos beneficiários. Considerando que o objetivo deste Programa é a segurança alimentar e nutricional dos estudantes, que podem estar com sua saúde física e cognitiva em risco, entendeu-se que os recursos do PNAES poderiam ser utilizados para compor o edital do PSAN.

${ }^{17}$ Em relação ao quantitativo de atendidos pelo PSAN, é preciso explicar que foi composto por duas ações simultâneas: o repasse do benefício de $\mathrm{R} \$ 200,00$ reais mensais à 248 famílias inscritas no edital e a entrega de kits
} 
antecedem-se diversas etapas: pedido dos alimentos aos fornecedores do PNAE, recebimento e armazenamento das mercadorias, montagem dos kits, articulação com o setor de transporte para providência das rotas de entrega (que implica cerca de seis municípios distintos), confecção dos Termos de Doação (documento necessário para o repasse dos alimentos aos estudantes), articulação com o setor de Tecnologia da Informação para impressão dos termos, contato com cada estudante para aviso das datas previstas e monitoramento das entregas.

Outro ponto importante que também merece destaque é a manutenção da compra de alimentos provenientes da agricultura familiar da região ${ }^{18}$ através do PNAE. Assim, o PSAN beneficia não só as famílias dos estudantes contemplados, mas também contribui para o fortalecimento de agricultores familiares locais, grupo este que vem sendo muito prejudicado durante a pandemia, devido à dificuldade de escoamento da sua produção e à precariedade e negligência de políticas públicas voltadas a ele.

Mesmo com o respaldo da Lei n. ${ }^{\circ}$ 13.987/2020, que autoriza, em caráter excepcional, a distribuição de gêneros alimentícios adquiridos com recursos do PNAE aos responsáveis dos estudantes das escolas públicas de educação básica, não é o que vimos observando em grande parte das cidades e estados, conforme descrito na matéria abaixo:

Embora a Lei 11.947 de 2009 assegure que, pelo menos, 30\% dos recursos da alimentação escolar sejam destinados para compra de legumes, frutas e verduras da agricultura familiar, não é o que está acontecendo neste período de crise. Segundo as entidades que lançaram, na última sexta-feira, a campanha Agricultura Familiar é Saúde na Alimentação Escolar, muitos prefeitos e governadores estão deixando de comprar de famílias agricultoras e comprando de grandes redes de supermercados. São na grande maioria alimentos ultra-processados, produzidos com matériasprimas artificiais e poucos ingredientes frescos, saudáveis e sem agrotóxicos, em um momento em que os brasileiros precisam fortalecer as defesas naturais do organismo. (OLIVEIRA, 2020) ${ }^{19}$

Posto isto, o PSAN vem se caracterizando como uma ação de suma importância em período de estado de emergência, como na pandemia atual, e seu acesso contínuo aos estudantes, que a qualquer tempo possam se encontrar em situação de insegurança alimentar, nos permite o conhecimento e o acionamento de medidas mais precocemente.

de alimentos, cujo número de atendidos chegou ao montante de 120 estudantes, dentro desses 248, que além do valor em dinheiro recebeu mensalmente os kits de alimentos. A seleção para o recebimento concomitante de ambos os benefícios se deu observando a classificação de segurança alimentar familiar e as condições socioeconômicas das famílias por meio do trabalho de análise da equipe interdisciplinar.

${ }^{18}$ Sobre os gêneros alimentícios ofertados nos kits de alimentos mensais, a equipe tem o cuidado de intercalar kits de alimentos perecíveis, principalmente hortifrutigranjeiros, e de alimentos não perecíveis. O PNAE prevê por lei a destinação de, no mínimo, 30\% dos recursos repassados pelo Fundo Nacional de Desenvolvimento da Educação (FNDE) para compra de alimentos oriundos da agricultura familiar.

${ }^{19}$ Matéria publicada na Rede Brasil Atual, cf. referências bibliográficas. 
Muitos foram os desafios, em especial os decorrentes das dificuldades técnicas e operacionais na entrega dos kits de alimentos aos estudantes em suas residências, a articulação entre setores, a comunicação com os estudantes e, até mesmo, o armazenamento e deslocamento dos gêneros alimentícios perecíveis. Essas questões, apesar de complexificar a execução do Programa, levando por vezes a momentos de desânimo, nos fizeram amadurecer e alcançar, paulatinamente, maiores êxitos.

Estudos recentes apontam para a importância e a necessidade da interdisciplinaridade nas ações da assistência estudantil a fim de alcançar um atendimento mais amplo e eficaz às demandas apresentadas pelos estudantes (FERREIRA, A. M. S. A, et. al, 2019; FREIRE, T. S., 2018). Outro estudo também traz que a interdisciplinaridade "[...] é sinônimo de abertura para o diferente, de respeito pela posição alheia, ao nos advertir para os nossos erros e limites e ao fornecer sugestões, é necessária ao próprio desenvolvimento de nossa posição e, de modo geral, da ciência” (COUTINHO, 1991, apud VASCONCELOS, 1997, p. 134). Ou seja, o trabalho interdisciplinar é rico em sua própria concepção e percepção, uma vez que propicia a troca de saberes e a complementação de competências para a ampliação da capacidade de alcance dos objetivos almejados nas ações profissionais.

Por fim, cabe sinalizar que o PSAN ainda está sendo executado e desenvolvido durante a escrita deste artigo. Portanto, nossas considerações socializadas são parciais. Porém, a trajetória até aqui empenhada reafirma a relevância e potência deste trabalho, desenvolvido durante a pandemia e para além dela, suscitando necessárias reflexões sobre a relação entre assistência estudantil e alimentação escolar, que continuaremos a fortalecer.

\section{CONSIDERAÇÕES FINAIS}

O trabalho apresentado resultou de um esforço coletivo da equipe para agregar conhecimentos diversos, com respeito mútuo às suas competências e à capacidade de acrescentar ao saber individual.

Nesse sentido, consideramos alguns pontos de reflexão e aprendizado no processo de criação do PSAN, como: a importância do debate sobre assistência estudantil e alimentação escolar, a relevância do trabalho interdisciplinar na política de assistência estudantil e a necessidade de construção de uma política para além da oferta de auxílios e bolsas.

Pensar na importância da alimentação escolar na qualidade de vida dos estudantes tornou-se imperioso à equipe multiprofissional do campus, isso porque a alimentação, elemento 
básico para garantia do direito à educação, enfrenta largos e profundos desafios na Rede de Educação Profissional e Tecnológica, sobretudo no que se refere ao desenvolvimento de políticas de atendimento que contemplem, de forma isonômica, os estudantes em seus diversos níveis e modalidades de ensino.

Para tanto, ficou evidente que quaisquer que fossem as reflexões e propostas criadas para a alimentação escolar, dentro da política de assistência estudantil de uma instituição como o IFFluminense, era imperioso que surgissem de um trabalho interdisciplinar. Dessa maneira, o desenvolvimento do referido Programa comprova a importância do trabalho em equipe e seu profícuo caminho na construção de uma política de assistência estudantil integral, para além de benefícios financeiros. Como exemplo, construímos atividades educativas, como rodas de conversas durante o setembro amarelo, abordando desde o acesso às políticas públicas de saúde mental até a alimentação saudável e sua correlação com o tema. Essa atuação dos profissionais em conjunto, revelou que os conhecimentos se complementam e alimentam as necessidades estudantis diversas.

Por fim, a busca por alternativas no atendimento às demandas estudantis, diante deste cenário devassador de pandemia, evidenciou que as ações anteriormente ofertadas aos estudantes do IFFluminense, Campus Macaé, no tocante à assistência estudantil, não mais são suficientes por si só. Assim, a experiência deste trabalho nos deixou o legado de que é preciso se reinventar e criar novos caminhos, numa perspectiva mais ampla e integral, abarcando as múltiplas visões dos profissionais que atuam na política de assistência estudantil.

\section{REFERÊNCIAS}

BRASIL. Lei $\mathrm{n}^{\mathrm{o}} 11.346$ de 2006. Disponível em: http://www.planalto.gov.br/ccivil 03/ ato2004-2006/2006/lei/111346.htm Acesso em: 10 de outubro de 2020.

Lei $\mathrm{n}^{\mathrm{O}} \quad 11.947$ de 2009. Disponível em: http://www.planalto.gov.br/ccivil 03/ ato2007-2010/2009/lei/111947.htm Acesso em: 10 de outubro de 2020. 
—. Decreto 7.234 de 2010. Disponível em: http://www.planalto.gov.br/ccivil 03/ ato2007-2010/2010/decreto/d7234.htm Acesso em: 10 de outubro de 2020.

Ministério do Desenvolvimento Social e Combate à Fome. Secretaria de Avaliação e Gestão da Informação. Estudo Técnico No 01/2014. Escala Brasileira de Insegurança Alimentar - EBIA: análise psicométrica de uma dimensão de Segurança Alimentar e Nutricional. Brasília-DF, 2014.

- Lei $\mathrm{n}^{\circ} \quad 13.987$ de 2020. Disponível em: http://www.planalto.gov.br/ccivil 03/ ato2019-2022/2020/lei/113987.htm Acesso em 10 de outubro de 2020.

CFN - CONSELHO FEDERAL DE NUTRICIONISTAS. Nota Pública sobre a execução do PNAE durante o período de estado de calamidade pública e da emergência de saúde pública decorrente do novo coronavírus. Brasília-DF, 2020.

CROSARA, Daniela de Melo \& SILVA, Leonardo Barbosa. A assistência estudantil em debate: análise dos projetos de lei em tramitação no Congresso Nacional Brasileiro. Curitiba: Publishing, 2020.

FERREIRA, Alana Mara Santos dos Anjos. et al. Desafios e Possibilidades de Atuação da Equipe Multidisciplinar de Atenção ao Estudante da Universidade do Estado da Bahia. In: Anais do XIX Colóquio Internacional de Gestão Universitária, Florianópolis - SC, 2019.

FREIRE, Thamyres Siqueira. Assistência Estudantil em tempos de incertezas: interdisciplinaridade como estratégia? Trabalho de Conclusão de Curso, Graduação em Serviço Social. UFF, Campus Campos dos Goytacazes, RJ, 2018.

GOMES, Thalles. Direito à alimentação escolar em tempos de pandemia. Artigo publicado no Jornal Brasil de Fato. São Paulo-SP, 2020. Disponível em: https://www.brasildefato.com.br/2020/04/05/artigo-direito-a-alimentacao-escolar-emtempos-de-pandemia Acesso em 08/10/2020.

IFFLUMINENSE. Instituto Federal Fluminense. Resolução No 39. Política de Assistência Estudantil do IFFluminense. Campos dos Goytacazes-RJ, 2016. 
LIMA, Gleyce Figueiredo. Educação Pública e Combate à Pobreza: a política de assistência estudantil no IFRJ/Campus São Gonçalo (2008 2015). Tese de doutorado. PPGSS/UFRJ. Rio de Janeiro, 2017.

LINDER, Larissa. Alta dos alimentos deve agravar insegurança alimentar no Brasil. Uol Economia. 11/09/2020. Disponível em: https://economia.uol.com.br/noticias/deutschewelle/2020/09/11/alta-dos-alimentos-deve-agravar-inseguranca-alimentar-no

brasil.htm?cmpid=copiaecola Acesso em: 09/10/2020.

OLIVEIRA, Cida de. Gestores públicos deixam produção da agricultura familiar fora da merenda escolar. Matéria Rede Brasil Atual de 22/07/2020. Disponível em: https://www.redebrasilatual.com.br/saude-e-ciencia/2020/07/gestores-publicos-deixamproducao-da-agricultura-familiar-fora-da-merenda-escolar/ Acesso em 10/10/2020.

PINTO, Giselle. A política de assistência estudantil da UFF em duas faces: a institucionalidade dos processos e as perspectivas da demanda estudantil. 2015 Tese (Doutorado). Pontifícia Universidade Católica do Rio de Janeiro, 2015.

VASCONCELOS, Eduardo Mourão Vasconcelos. Serviço Social e Interdisciplinaridade: o exemplo da saúde mental. In: Serviço Social e Sociedade, nº 54, Julho, 1997, p. 132-157. 